\title{
Straddle Injury in Girls. A Pilot Study Testing Potential for an Injury Surveillance Registry
}

\author{
A. Fette ${ }^{*}, 1$ and L.G. Hörte ${ }^{2}$ \\ ${ }^{1}$ Drosselstr 4, D-71554 Weissach im Tal, Germany \\ ${ }^{2}$ Karolinska Institutet, Divison of Social Medicine, Department of Public Health Sciences, Norrbacka, 17176 Stockholm, \\ Sweden
}

\begin{abstract}
Objectives: Straddle injury represents a rare and complex injury to the female genito - urinary tract (GUT). Overall prevention would be the ultimate goal, but due to persistent inhomogenity and inconsistency in definitions and guidelines, or suboptimal coding, the optimal study design for a prevention programme is still missing. Thus, medical records data were tested for their potential use for an injury surveillance registry and their impact on future prevention programmes.
\end{abstract}

Design: Retrospective record analysis out of a 3 - year - period.

Setting: All patients were treated exclusively by the first author.

Patients: Six girls, median age 7 years, range 3.5 to 12 years with classical straddle injury.

Interventions: Medical treatment and recording according to National and International Standards.

Main Outcome Measures: All records were analyzed for accuracy in diagnosis and coding, surgical procedure, time and location of incident and examination findings.

Results: All registration data sets were complete. A specific code for "straddle injury" in International Classification of Diseases (ICD) did not exist. Coding followed mainly reimbursement issues and specific information about the injury was usually expressed in an individual style.

Conclusions: As demonstrated in this pilot, population based medical record data collection can play a substantial part in local injury surveillance registry and prevention initiatives planning.

Keywords: Straddle injury, injury surveillance registry, hospital record data.

\section{INTRODUCTION}

"Straddle injury" (SI) is a rare but always serious injury in girls. Primary prevention would obviously be the ultimate goal. But achieving this is difficult if research is limited, treatment standards inconsistent and coding still suboptimal or even rudimentary? Thus, hospital records were evaluated for their potential use for an surveillance registry, that might lead to greater future care and prevention of this underreported problem.

\section{TERMS AND DEFINITIONS}

The classic "straddle injury" (SI) is defined as an injury to the perineum as a result of falling on or striking a surface or object with the force of one's own body weight regardless of his/her gender. This mechanism compresses the soft tissues against the bony margins of the pelvic outlet, thereby causing injury [1-8]. Quite frequently SI is considered as a question of sexual abuse $[5,7,9]$, or as a cause of traumatic disruption of the urethra in male patients ( $\equiv$ non - classic SI) [7]. Unusual straddling - type mechanisms (三 miscellaneous

*Address correspondence to this author at Drosselstr 4, 71554 Weissach im Tal, Germany; Tel: +49 - 7191 - 53306; Fax: +49 - 7191 - 493947;

E-mail: andreas.fette@gmx.de
SI) are: break dancing, riding banana - seat bicycles, and go cart injuries [5]. Gynecologists subcategorized SI under nonobstetrical vulvovaginal injuries (VVI) [9], injury preventists as genito - urinary trauma after monkeybar injuries [10].

Injury surveillance is the continuing scrutinity of all aspects of occurence and patterns of injury that are pertinent to effective prevention and control. Preferable attributes of a surveillance system are: simplicity, flexibility, acceptability, reliability, utility, sustainability and timeliness [11]. The minimum data a surveillance system must collect on all injuries to be useful for injury surveillance purposes is the Core Minimum Data Set (Core MDS) [12, 13]. Included variables mandatory are listed in Table 1. The Core Optional Data Set (Core ODS) might be added to the Core MDS if it is deemed useful $[12,13]$. For variable details see Table 2. Supplementary data refer to additional data that a surveillance system can collect about specific types of injury [12].

Three - character - coding in ICD - 10 (International Classification of Disease) is the basic level of coding to the WHO mortality database (NB: ICD - $10(\mathrm{GM})=$ German Modification). The fourth character subcategories, even if not mandatory for reporting at the international level are 
recommended for many purposes and form an integral part of the ICD, as do the special tabulation lists $[11,14]$.

Table 1. Core Minimum Data Set
1) An unique identifier
2) Age
3) Sex
4) Intent
5) Place of injury
6) Type of activity
7) Mechanism or cause
8) Nature of injury

Table 2. Core Optional Data Set

1) Race
2) Date and time of injury
3) Injury severity
4) Disposition
5) Alcohol and drug involved

After identification of all injuries, the Main Injury Code should be assigned individual for each injury, with the most severe assigned as the main condition before the others are sequenced one by one $[11,14,15]$.

If relevant the Place of Occurence Code for the external cause of injury, or the activity at the time of incident - Activity Code - could be established [11,14]. Since both codes in ICD are very limited, the ICECI - International Classification of External Causes of Injury - coding system is preferable.

Other External Causes of Accidental Injury could be coded as optional as well $[11,14,15]$.

For health care reimbursement all procedures done within the ICD - 10 (GM) are finally coded in OPS 2007 (Operationen und Prozedurenschlüssel) [16] but no specific term or code "straddle injury" actually exists $[15,16]$. Coding alternatives are summarized in Table $\mathbf{3}$.

\section{PATIENT SAMPLE AND METHODS}

From July 2003 to July 2006 six girls $(\mathrm{n}=6)$ with a classic SI were admitted to the Children's Hospital Lucerne, Switzerland. Age ranged from 3.5 to 12 with a Median of 7 years. All patients were examined exclusively under general anesthesia with rectal - digital examination, cystoscopy and vaginoscopy. The lacerations were explored and sutured with absorbable stitches if indicated, and a urethra catheter inserted. Later the following day the catheter was removed, spontaneous voiding appreciated and the child discharged home. All records were finally assessed for:

- $\quad$ bio - and registration data

- history recording, location and time of incident, mechanism and external cause of injury, activity engaged, and first aid received

- $\quad$ appropriate recording of examination findings

- $\quad$ correct diagnosis and performed surgical procedures and final transformation into Core Data Sets and ICD coding.

Table 3. Specific "Straddle Injury" - coding at - a - Glance

\begin{tabular}{|c|c|}
\hline $\mathrm{S} 30.2$ & Contusion of the external genitals \\
\hline $\mathrm{S} 31.4$ & Open wound of vagina and vulva \\
\hline $\mathrm{S} 31.5$ & Open wound in genital area, no further specification \\
\hline S31.8 & $\begin{array}{l}\text { Open wound in the abdominal region, no further specifica- } \\
\text { tion }\end{array}$ \\
\hline S37.80 & Injury to the urethra, no further specification \\
\hline $\mathrm{S} 38.0$ & Contusion of the external genitalia \\
\hline T19.9 & $\begin{array}{l}\text { Foreign body in the uro - genital tract, no further specifica- } \\
\text { tion }\end{array}$ \\
\hline W49.9 & $\begin{array}{l}\text { Accident/Incident throughout exposition against the me- } \\
\text { chanical forces of non-living objects (including perforation) }\end{array}$ \\
\hline X59.9 & Accident/incident caused by falls, no further specification \\
\hline $1-661$ & Cystoscopy \\
\hline $1-670$ & Vaginoscopy \\
\hline $5-716.0$ & $\begin{array}{l}\text { Plasty and reconstruction of the vulva and perineum by } \\
\text { suture }\end{array}$ \\
\hline $5-716.1$ & Plasty by plastic surgical reconstruction \\
\hline $5-900.0 \mathrm{c}$ & $\begin{array}{l}\text { Simple reconstruction of skin and subcutis by primary suture, } \\
\text { genital area }\end{array}$ \\
\hline $5-549.0$ & Removal of foreign body out of the abdominal cavity \\
\hline $8-147 . x$ & Catheter drainage \\
\hline
\end{tabular}

\section{RESULTS}

All records were stored properly in the hospital archives according to National Medical Chamber Legislation Standards containing epicrisis and surgeon's procedure report. Registration data sets were coded accurately for health insurance reimbursement. ICD - 10 (GM) and OPS 2007 coding were stored on each patient's digital data file. Within the history section, location and time, mechanism of injury and activity engaged during the incident were reported in all cases, but expressed in a more individual style instead of using specific coding systems. Location of incident was the private bath room in four, respectively the public swimming pool area in two cases with slipping on the wet surface, crushing against (5 cases, pool/tub border) or being penetrated by ( 1 case, shower gel bottle) a solid object as most common mechanism of injury. Activity engaged was play and romp or an argument with a sibling or friend. Time of incident was the afternoon regarding the pool area (2 cases), respectively the early evening regarding the bath room (4 cases). Actually at time, when these children are preparing for going to bed. All injuries were timely recognized by and notified to the parents or guardians, mainly because of the bloody discharge from their genital area (Figs. 1 and 2), without delay in referral or "hiding behind" by the children themselves. No suspicion for a sexual assault was set - up in any case. All surgical procedures were performed exclusively by the first author.

\section{DISCUSSION}

To date, our modern health care system has a substantial need for high quality research and up - to - date injury databases. First, to be cost effective today, second, to stimulate 
future injury prevention. For this, an ongoing data analysis about our traditional and modern treatment modalities is mandatory leading to formulation of standards for high quality and effective care even in front of limited resources.

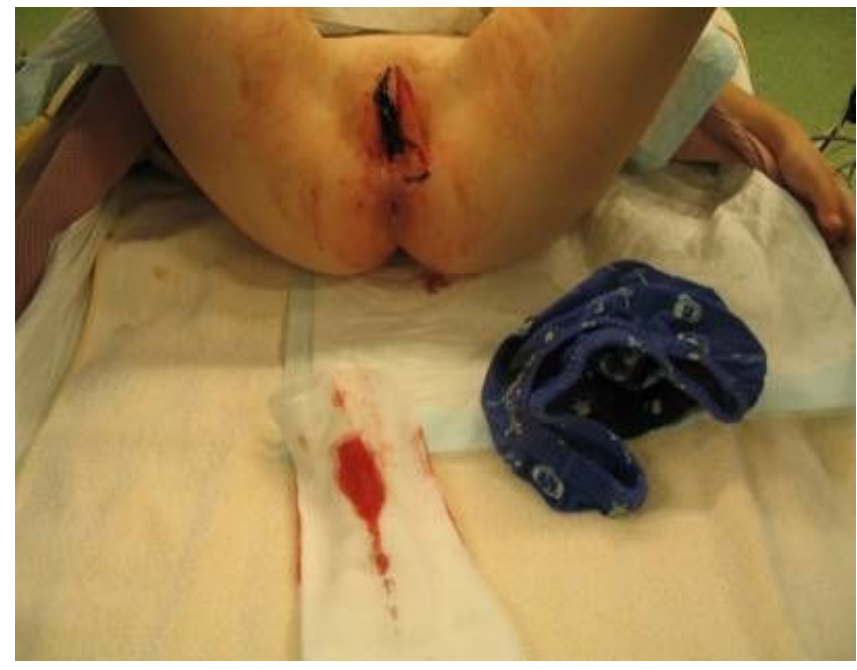

Fig. (1). Main complaint bloody discharge.

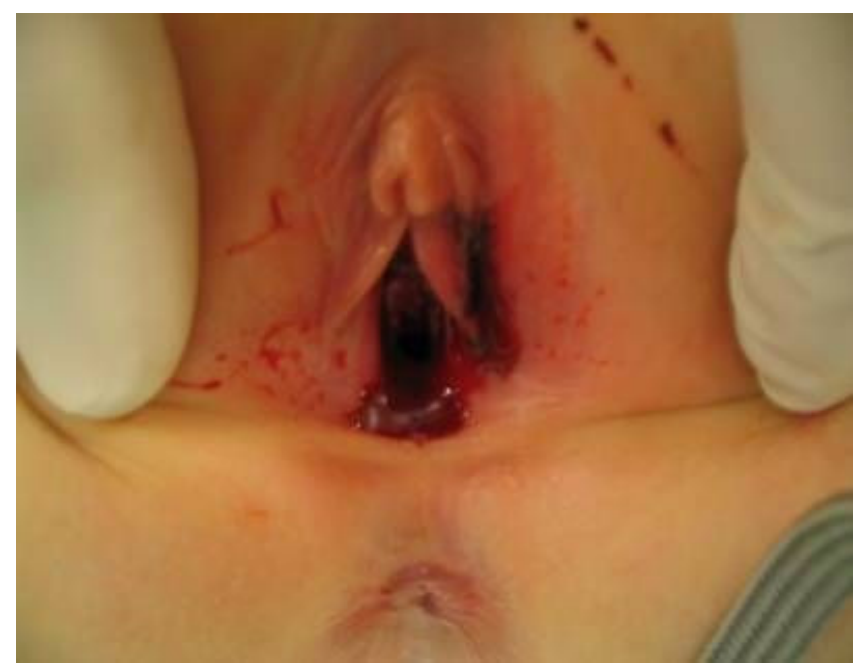

Fig. (2). Tears in labiar fold and posterior fourchette.

But classification is of key importance (William Farr, 1856). Because without this, broad description of the "same" injury will be used [1-10], assigning the "same" diagnosis or even the "same" code to a harder specifyable injury, resulting in inaccuracy. This inaccuracy may even be multiplied, if the injury per se is complex [3-5, 9], or the recognition of this specific injury is in anyway "different" in that particular hospital setting $[5,7,8]$. Since recommendations and guidelines do vary frequently in medical science and daily clinical practice $[3-5,7,8,17]$, this will certainly not facilitate accurate coding, making sometimes proper comparison nearly impossible, like eg straddle injury in girls.

Obviously, a high incidence and prevalence rate, or a sexy topic will have the greatest impact on society and public interest. Etiology, demographics, cultural and socio economic issues come into play, too, influencing all current or future trends in different ways. With six "typical" straddle injuries treated in a 3 - years - time, or others reporting about nine children in 12 [6] respectively seventeen in 7 years [9], such a rare occurance will surely not stimulate any interest of stakeholders, health care managers, politicans and prevention activists at all. Figures for prevalence and incidence are coincident with $3 \%$ for genito - urinary tract injuries respectively 1: 2000 for all trauma admissions [5,6,9,10]. Therefore, evidence levels have to be based on case series only, which is considered to be less meaningful in medical science [18], especially if not even a specific (DRG -) code "straddle injury" exists like for other GUT injuries [15].

The Center for Disease Control (CDC) and the National Academy of Science recommended that all injury surveillance systems include data about time, place, person, type, cause and circumstances of injury, as well as medical care and outcome making (E -) codes of particular importance [19]. Guyer et al. examined feasibility and usefulness of hospital discharge data, coded by both the nature ( $\mathrm{N} \mathrm{-}$ ) and external cause (E -) code as essential component of their national injury surveillance system [20]. Based on a retrospective case note review Holland and coworkers collected data on the mechanism of injury (MOI), clinical features, radiological investigations, management, complications, and long term outcome [6]. While another group focused on accurate history taking, time of incident and evidence of previous ED attendances. Their documentation further included weight, height and centiles of the children, evidence of a detailed account of genital findings, accompanying non - genital injuries and the final case management [5]. According to the The Joint Commission on the Accreditation of Health Care Organizations (JCAHO) ED records should include data about patient identification, times and means of arrival, pertinent history and physical findings. Additionally, data about emergency care given before hospital arrival, diagnostic and therapeutic orders, clinical observations, results and reports of procedures, and final disposition [19]. Others collected specifically data on patient demographics, clinics, type, cause and outcome of injuries [21], or eg referal source and GP code, mode of arrival and triage category [22]. It is rather obvious that the great variety in CDS chosen above is as various as their intended purposes providing finally no evidence at all. Our chosen CDS was based on published (international) guidelines $[12,13]$, derived from national standards given by the medical chamber and represented common clinical practice.

Greaney et al. scoring system tested real accuracy in the notes assuming ideal practice and application in all cases. Two records scored greater than $50 \%$, one less than $25 \%$, and the remaining fourteen between $25 \%$ and $50 \%$. Often the genital injuries were described incompletely and children warranting a pediatrican assessment have not been refered as given by the action score chart [5]. Colleagues distributed a questionaire asking about the number of patients, information collected and coded in the ED record and storage modalities. As a general result, the higher volume EDs collected more information than the lower volume facilities. Data storage varied from $31 \%$ for E-codes to $66 \%$ for demographic information, direct accessability in the ED from a few weeks to permanent [19]. Although all EDs record the chief complaint and most record information about the cause of injury, only a very small percentage recorded by real Ecodes, and less than a third having E-codes already recorded, finally include these codes in their stored files [19]. Such "data loss" is comparable to the results of our study. 
This relative lack of codes and severity information reduces the utility of these records for surveillance purposes unnecessarily, as mentioned by Runyan et al. [19]. Others summarized their overall results accordingly as "poor recording" and recommended the use of a proforma, called Action Score Chart, that offers guidelines for further examination and follow - up of the patients. According to this chart, special cases should be refered to the pediatrican, but finally these (specialist) departments displayed not better results [5]. As already mentioned, in our setting the majority of these cases are managed by pediatric surgeons. Basic statistics done, quality of data sources, age range $[5,7,9,10]$, or retrospective single reviewer data collection [7] were similar between our study design and the literature review. Duration of the study was comparable [7] or even longer [9].

Focusing on established injury surveillance methodologies the current knowledge in the United States derived mainly from mortality statistics. Data that constituted for less than $0.1 \%$ of all injuries reaching such medical attention [20]. But death reflects just the tip of the iceberg, since as many as 330 visits to hospital EDs are estimated for every injury death [19]. But to date, no national surveillance system for non - fatal injuries exists [20]. To counteract, Habek and Kulas tested morbidity data as source for their surveillance system "straddle injuries in girls", but the overall morbidity was too low and unspecific, although straddle injuries represented $75 \%$ of all genital injuries in their sample [9].

Using hospital discharge data instead of deaths would increase the number of cases available for analysis by 40 , as shown in the Massachusetts Statewide Childhood Injury Prevention Programm (SCIPP) study [20]. To some extent comparable results are reported by Kirsch et al. [20]. Such uniform hospital discharge data sets (UHDDS), already collected nationwide for fiscal reasons, would also provide information about patterns of injuries and facilitate inter researcher comparison [20]. Further, such UHDDS would be continously available, providing demographic and descriptive variables for analysis, facilitate the assessment of the financial burden of injuries, or facilitating interstate comparison [20]. Not only in McKenzie`s point of view, this will stimulate future decisions on prevention policies [20, 21].

For ED records as main data source it is stated that there is no standardized reporting system and the type of principal obtainable data are not well documented $[19,20]$. Than, even if more than $97 \%$ of the respondents indicated that information about the cause of injury has been recorded [19], - similar to our results, history taking in the emergency department is usual accomplished by the physician while doing a physical examination, and not in that kind of systematic manner that lend itself to coding [19]. Most likely such "frontline" data will represent the "real life and reality" best, however, it will be an ongoing matter of debate, if such kind of information or data reporting will be insufficient to derive E-codes, anyway [19]. Then collected by a large number of clinicians or medical staff, inconsistency and inaccuracy will always occur [20]. Or certain injuries will be underrepresentated, because either an in- or outpatient setting or a specialist department being in charge for [20].

It is obvious, that such data alone are not sufficiently robust for single practical use in any surveillance system. A final accurate diagnosis is key, followed by a specific code, preferably combining both injury and diagnosis. Such a code will provide policy makers with information concerning the type of injury that lead to a specific form of trauma [20] and vice versa (authors' opinion). But so far, no such specific diagnosis or code "straddle injury in girls" exists. Coding this data by N Code only is not sufficient, including E-codes in the routine data collection should follow $[12,19,20]$. Because coded by both, $\mathrm{N}$ and E-code, is considered to be the appropriate next step in the development of a good national surveillance system [20].

First, it may be found difficult to endorse investment in $\mathrm{E}$ coding [20]. However, this E-code information is still considered to be the least expensive way to obtain these data, most simply by adding an additional E-code field to the computerised form [20]. As demonstrated above, alternatively these E-codes could be created out of the in individual style collected patient's history data already taken on admission.

In perspective of creating a "perfect" injury surveillance system the NOMESKO - Code" was applied by Alberts et al. on a first - time ED record set [23]. But many problems regarding validity and reliability have to be faced since the average shortfall in filling in the NOMESKO - Codes on the registration form was $10 \%$, rating highest for "activity" (13 $\%)$ and lowest for "cause of visit" (6\%) [23]. Actual place of injury was not filled in properly in $23 \%$ of entries making it impossible to code the $\mathrm{E}$ - Code in $11 \%$, and the diagnosis in $4 \%$ [23]. This overall lack in quality of data sets is imminent in this study, too and might only be improved by more personal experience, training and enthusiasm of "lay" coders or by appointing exclusively professional ones.

*The NOMESKO - Code is used for classification of data from injury surveillance studies. This classification system is multi - axial and describes the external causes of unintentional injuries, assault, and self - inflicted injury by including cause of visit, acitivity, type of location, and mechanism of injury. Contributing factors, diagnosis, E - Code and treatment were also recorded.

\section{KEY MESSAGES}

What is already known on this subject:

- $\quad$ injury surveillance is the crucial first step to reduce the burden of injury worldwide

- no perfect study design for an injury surveillance registry already exists

- no sufficient coding and classification for "straddle injuries in girls" exist

What this study adds:

- demonstrate the urgent need for a specific code for "straddle injuries in girls"

- the quality of our (actual) hospital data sets can identify (local) trends (best) and pointing out urgent needs for injuy prevention measures

- if overall quality and accuracy in data - coding transfer could be stimulated more global impact might be possible as well 


\section{REFERENCES}

[1] Friedbichler I, Friedbichler M. Fachwortschatz Medizin Englisch: Georg Thieme Verlag Stuttgart 2003.

[2] Bunjes WE. Medical and Pharmaceutical Dictionary English German. $4^{\text {th }}$ ed. Georg Thieme Verlag Stuttgart: New York 1981.

[3] Kurth KH. Verletzungen in Altwein JE, Jacobi GH (Eds): Urologie, Enke Verlag, Stuttgart: Auflage 1979; 2.

[4] Dietz HG, Schuster T, Stehr M. Operative Eingriffe in der Kinderurologie. Ein Kompendium. Medizin \& Wissen, Urban \& Vogel: München 2001.

[5] Greaney H, Ryan J. Straddle injury - is current practice safe? Eur J Emerg Med 1998; 5 (4): 421- 24.

[6] Holland AJ, Cohen RC, McKertich KM, et al. Urethral Trauma in Children. Pediatr Surg Int 2001; 17 (1): 58-61.

[7] Dowd MD, Fitzmaurice L, Knapp JF, et al. The interpretation of urogenital findings in children with straddle injuries. J Pediatr Surg 1994; 29: 7-10.

[8] Acuna TV. Emergency management of "straddle injuries". J Philipp Med Assoc 1964; 40: 958-59.

[9] Habek D, Kulas T. Nonobstetrics vulvovaginal injuries: mechanism and outcome. Arch Gynecol Obstet 2007; 275(2): 93-7.

[10] Waltzmann ML, Shannon M, Bowen AP, et al. Monkeybar injuries: Complications of Play. Pediatrics 1999; 103: 58.

[11] International PhD Course on Internet "Injury Surveillance and Coding", Karolinska Institutet, Stockholm, Course Materials, October $2^{\text {nd }}, 2006$ - April $30^{\text {th }}, 2007$,

[12] McGee K, Peden M, Waxweiler R, et al. Short Report Injury Surveillance. Inj Control Saf Promot 2003; 10 (No 1 - 2): 105-8.

[13] Injury surveillance guidelines. www.who.int/violence_injury_pre vention [accessed February 2007].

[14] ICD - 10 Buch, Course Materials, International PhD Course on Internet "Injury Surveillance and Coding" 2006-2007.

[15] Deutschland ICD - 10 - GM 2007, Systematisches Verzeichnis, Internationale statistische Klassifikation der Krankheiten und verwandter Gesundheitsprobleme, 10. Revision - German Modifica- tion, Version 2007, Stand 9. Oktober 2006. Bearbeitet von Dr. med. Bernd Graubner, Zentralinstitut für die kassenärztliche Versorgung in der Bundesrepublik Deutschland (ZI), Deutscher Ärzteverlag: Köln. www.ki.se

[16] OPS 2007, Systematisches Verzeichnis mit Erweiterungskatalog, Operationen- und Prozedurenschlüssel, - Internationale Klassifikation der Prozeduren in der Medizin, Version 2007. Deutsches Institut für Medizinische Dokumentation und Information (DIMDI) im Auftrag des Bundesministeriums für Gesundheit unter Beteiligung der Arbeitsgruppe OPS des Kuratoriums für Fragen der Klassifikation im Gesundheitswesen (KKG). Bearbeitet von Dr Bernd Graubner, Zentralinstitut für die kassenärztliche Versorgung in der Bundesrepublik Deutschland (ZI), Deutscher Ärzteverlag: Köln. www.ki.se

[17] Jordan GH, Virasora R, Eltahawy EA. Reconstruction and management of posterior urethral and straddle injuries of the urethra Urol Clin North Am 2006; 33(1): 97-109.

[18] Ajetunmobi O. Making sense of critical appraisal, Arnold Publisher London: Oxford University Press 2002.

[19] Runyan CW, Bowling JM, Bangdiwala SI. Emergency department record keeping and the potential for injury surveillance. J Trauma 1992; 32: 187-89.

[20] Guyer B, Berenholz G, Gallagher SS. Injury surveillance using hospital discharge abstracts coded by external cause of injury (ecode). J Trauma 1990; 30: 470-73.

[21] Kirsch TD, Beaudreau RW, Holder YA, et al. Pediatric injuries presenting in an emergency department in a developing country. Pediatr Emerg Care 1996; 12: 411-15.

[22] Lyons RA, Lo SV, Heaven M, et al. Injury surveillance in children - usefulness of a centralised database of accident and emergency attendencances. Inj Prev 1995; 1: 173-76.

[23] Alberts KA, Goldie I, Edler D, et al. Injury surveillance at emergency departments in an urban area. Methodology and quality control. Scand J Prim Health Care 1991; 9: 239-43. 